\title{
Elvis to Eminem: quantifying the price of fame through early mortality of European and North American rock and pop stars
}

\author{
Mark A Bellis, Tom Hennell, Clare Lushey, Karen Hughes, Karen Tocque, John R Ashton
}

J Epidemiol Community Health 2007;61:896-901. doi: 10.1136/jech.2007.059915

See end of article for authors' affiliations

Correspondence to: Mark A Bellis, Centre for Public Health, Liverpool John Moores University, Castle House, North Street, Liverpool L3 2AY, UK; m.a.bellis@ljmu.ac.uk

Accepted 6 April 2007

\begin{abstract}
Background: Rock and pop stars are frequently characterised as indulging in high-risk behaviours, with highprofile deaths amongst such musicians creating an impression of premature mortality. However, studies to date have not quantified differences between mortality experienced by such stars and general populations. Objective: This study measures survival rates of famous musicians $(n=1064)$ from their point of fame and compares them to matched general populations in North America and Europe.

Design: We describe and utilise a novel actuarial survival methodology which allows quantification of excess post-fame mortality in pop stars.

Participants: Individuals from North America and Europe performing on any album in the All-Time Top 1000 albums from the music genres rock, punk, rap, R\&B, electronica and new age.

Results: From 3 to 25 years post fame, both North American and European pop stars experience significantly higher mortality (more than 1.7 times) than demographically matched populations in the USA and UK, respectively. After 25 years of fame, relative mortality in European (but not North American) pop stars begins to return to population levels. Five-year post-fame survival rates suggest differential mortality between stars and general populations was greater in those reaching fame before 1980.

Conclusion: Pop stars can suffer high levels of stress in environments where alcohol and drugs are widely available, leading to health-damaging risk behaviour. However, their behaviour can also influence would-be stars and devoted fans. Collaborations between health and music industries should focus on improving both pop star health and their image as role models to wider populations.
\end{abstract}

$\mathrm{F}$ amous pop and rock stars are frequently characterised as having "live fast, die young" lifestyles. ${ }^{12}$ Thus, media regularly document music celebrities who die prematurely, often with drug or alcohol abuse implicated either directly in their death (eg, overdose of Janis Joplin) or in association with fatal accidents or mental health conditions (eg, suicide of Kurt Cobain). However, while qualitative reviews support rock and pop stars suffering high levels of stress, depression and substance use, ${ }^{2-4}$ quantitative studies of mortality amongst such individuals are almost completely absent. ${ }^{5}{ }^{6}$ Consequently, discussions of premature mortality in pop and rock stars typically rely on cursory comparisons of musicians' ages of death with life expectancy in the general population. However, such calculations are likely to be misleading for several reasons. Young deaths of popular musicians receive widespread media coverage, yet relatively little attention is paid to numerous premature deaths routinely occurring in the general population (for instance, in 2004 there were 43146 deaths under the age of 55 in England and Wales and 373074 in the USA). ${ }^{78}$ Pop and rock stars can disappear from public attention as they age and deaths in older musicians may go relatively unnoticed, leaving a disproportionate impression of premature death. The pop star phenomenon is also a relatively recent cultural development and, with many stars still young, higher ratios of young to older deaths are inevitable. Furthermore, this same effect will reduce the proportion of deaths from cancer and heart disease and elevate proportions from causes more common to youths (ie, alcohol, drugs, accidents, suicides and violence). ${ }^{9}$

The numbers of individuals who achieve pop star fame are relatively small, and while their morbidity and mortality may be of major concern to the music industry, ${ }^{10}$ their direct contribution to population health statistics is minimal. However, the actions and behaviours of pop and rock stars are watched worldwide by millions of fans, would-be performers and performing musicians who follow their genre's leaders. Such stars are important role models for young people and can be influential in shaping their behaviour and identity. ${ }^{11-13}$ Thus, being a fan of certain music genres is associated with higher levels of drug use (eg, house music, ${ }^{14}$ hard rock and heavy metal $)^{15}$ and a variety of other risk-taking behaviours (eg, "hard" rap and violence, ${ }^{16}$ heavy metal and sexual behaviour). ${ }^{17}$ Consequently, the behaviour and resultant morbidity and mortality associated with rock and pop stardom may have a disproportionate influence on the health of the wider population. Furthermore, public health interventions are now utilising rock and pop stars in health promotion campaigns (eg, Jon Bon Jovi in a US anti-drugs campaign). ${ }^{13}$ However, such interventions are developed with few measures of how music fame relates to ill health or examination of the risks posed by associating health messages with potentially risk-taking lifestyles. Using a cohort of famous musicians $(n=1064)$ from a range of popular music genres, we measure survival rates from their point of fame, compare them to matched general populations in North America (USA and Canada only) and Europe and, based on our findings, examine both their own health prospects and the positive and negative contributions pop stars can make to public health. In doing so we explore a novel methodology for examining survival in a specific population where lack of population denominators precludes conventional techniques.

\section{METHODS}

In 2000, an international poll of over 200000 individuals (fans, experts and critics) identified the All-Time Top 1000 Albums. ${ }^{18}$ Being a solo performer or group member with a listed album was the primary inclusion criterion defining the cohort of pop stars (although compilation and soundtrack albums were excluded, $\mathrm{n}=1 \mathrm{l}$; table 1). Using websites (eg, allmusic.com, wikipedia. org, billboard.com, theofficialcharts.com, softshoe-slim.com and 
answers.com), biographies, encyclopaedias and published anthologies, ${ }^{1} 1920$ individuals' dates of birth, survival status on 31 December 2005 (alive or dead) and, where appropriate, date and reported cause of death were identified (tables 1 and 2). Individuals were excluded where date of birth or nationality was unknown (table 1) and those from the music genre classifications of country, blues, jazz, vocal, celtic, folk, bluegrass and spoken word were also removed leaving only the mainstream popular categories of rock, punk, rap, R\&B (rhythm and blues), electronica and new age. ${ }^{21}$ Finally, as only European and North American pop and rock stars were present in sufficient numbers to generate survival curves, the final sample was limited to these geographical areas, therefore excluding artists of other nationalities (eg, Bob Marley). To provide an objective measure of age at fame, we used pop stars' age at the earliest date of chart success $(n=807)$ or release of their earliest album in the AllTime Top 1000 Albums $(n=257)$. Chart success was measured as when an individual first appeared on an album in the Top 40 UK Official Chart $(\mathrm{n}=488)$ or Top 40 USA Billboard 200 $(\mathrm{n}=187)$. For those never having Top 40 albums, a Top 40 single in the UK chart $(n=27)$ or USA Billboard Hot $100(n=1)$ was substituted and, for remaining artists, a Top 40 album or single in a specialist US chart (Pop, $\mathrm{n}=84$; Black, $\mathrm{n}=13$; Heatseekers, $n=7$ ) was used. Thus, the earliest date of fame was 1956 for Elvis Presley and the latest 1999 for Eminem (Marshal Mathers).

For each pop star, we calculated total years of survival since becoming famous and compared this to their expected survival based on general populations (matched to pop stars for sex, nationality, ethnicity and age at the point of fame). Here, we utilised the actuarial survival method (ie, age standardised relative survival). ${ }^{22}$ This method matches each artist in the dataset with the corresponding annual survival probabilities experienced by an average individual of the same age and sex (and race) in the general population in or near their year of fame. Reference survival probabilities are taken from cohort life tables (ie, historic survival expectation of a group of individuals with the same year of birth). Thus, for European artists, we used UK historic cohort male and female life tables (1956-99 tables $)^{23}$ with population denominators adjusted using the 2001 UK census. Equivalent cohort life tables have been published annually for US populations, but the race-specific population

Table 1 Sample selection: exclusions and inclusions from the All Time Top 1000 Albums

\begin{tabular}{lc}
\hline & Number (\%) \\
\hline Albums & $1000(100.00)$ \\
Excluded & $2(0.20)$ \\
Compilation albums & $9(0.90)$ \\
Soundtracks & $222(22.20)$ \\
Additional albums by artists already included* & $767(76.70)$ \\
Included & $1285(100.00)$ \\
Individuals (from 767 albums) & $78(6.07)$ \\
Excluded & $40(3.11)$ \\
Excluded genre† & $1(0.08)$ \\
Not from North America or Europe & $1166(90.74)$ \\
Classed as a missing person & $36(3.09)$ \\
Included & $2(0.17)$ \\
Missing data (from 1166 individuals) & $64(5.49)$ \\
No nationality and date of birth & $1064(91.25)$ \\
No nationality & No date of birth \\
Included (final sample) & \\
\hline *Where additional albums included new band members such individuals \\
were also included in the final dataset. \\
†Genres: R\&B (rhythm and blues), rock, electronica, new age, punk and rap \\
were included and bluegrass, blues, vocal, celtic, country, folk, jazz and \\
spoken word were excluded.
\end{tabular}

denominators used are known to have been problematic, especially in the period 1980-91. ${ }^{24}$ Therefore, we estimated cohort tables from the US decennial (period) life tables ${ }^{25}$ applying survival rates from the 1959-61 decennial tables to the years 1956-64, survival rates from the 1969-71 tables to the years 1965-74 and so on. No decennial tables have been published for 1999-2001, so we applied corresponding annual period life tables for 2001. Cohort life tables were then estimated from the successive period life tables by use of an offset transposition matrix. Race-specific US tables were calculated for whites (male and female) and blacks (male and female) (in 1959-61 decennial tables, "non-white" was used as black was not specified). Hence, six sets of life tables were utilised to generate reference survival rates: UK males, UK females, US black males, US black females, US white males and US white females. Age standardised relative survival was calculated for all years up to the end of 2005 as pop star survival expressed as a percentage of the average of the corresponding survival probabilities from the matched reference populations. Confidence intervals (95\% CIs) were also calculated. As there are no calibrated CIs for survival probabilities in the UK national life tables, differences are assumed to be significant when matched population survival rates fall outside of the $95 \%$ CIs for pop stars. For other comparisons, statistical significance was assessed using $\chi^{2}$ and Mann Whitney U tests undertaken in SPSS.

\section{RESULTS}

In the final sample $(\mathrm{n}=1064)$, North American and European pop stars did not differ significantly in year of birth or sex although North American stars were more likely to be R\&B or rap artists (table 2). Overall, 100 pop stars had died (table 2) with $7.3 \%$ of women having died and $9.6 \%$ of men $\left(\chi^{2}=0.550\right.$, $\mathrm{p}=0.458)$. Crude mortality for European artists was around half that for North American artists (table 2) with median age of death among those who had died being 41.78 and 35.18 years for North American and European pop stars, respectively $(\mathrm{Z}=0.322, \mathrm{p}=0.747)$. Mortality just 5 years post fame was $2.4 \%$ overall but dropped from $3.5 \%$ in those reaching fame before 1980 to $1.6 \%$ in following years $\left(\chi^{2}=4.172\right.$, $\mathrm{p}<0.05)$. In both North American and European samples, a chronic drug- or alcohol-related problem or overdose was identified as associated with over a quarter of deaths (table 2). There were non-white artists in both European and North American samples with European pop stars being more likely to be white (table 2). Although numbers of deaths were small, crude mortality for non-white pop stars in North America ( $16.82 \%$ died) was higher than that for whites $(11.89 \%)$, although this failed to reach statistical significance $\left(\chi^{2}=1.880\right.$, $\mathrm{p}=0.170)$. Mortality rates for North American white stars $(11.89 \%)$ were also higher than those for European white stars (5.74\%; $\left.\chi^{2}=11.217, \mathrm{p}<0.001\right)$. Such analyses, however, do not account fully for the age and sex composition of populations, nor for the extent to which differential survival of the general populations in North America and Europe may also have affected pop stars. To address these issues, we calculate survival relative to the general population standardised by age, sex and, in North America, ethnicity.

Figure 1 presents the age standardised relative survival in both continents by years of fame. Relative survival is consistently below $100 \%$ for both European and North American artists (ie, pop star survival is always below that of the matched general populations). In the first year of fame, the upper confidence limit exceeds 100\% of the matched population survival for both European and North American artists, and for North American artists this is also true for the second year of fame. However, with the exception of the European sample in 
Table 2 Characteristics of pop stars sample by geographical region

\begin{tabular}{|c|c|c|c|c|}
\hline Characteristics & Total & Europe & North America & $\mathbf{p}^{*}$ \\
\hline Sample size (n) & 1064 & 503 & 561 & \\
\hline Main country (\%) & UK and USA, 94.64 & UK, 94.43 & USA, 94.83 & 0.773 \\
\hline Year of birth (median) & 1957 & 1957 & 1956 & 0.597 \\
\hline Year of fame (median) & 1981 & 1980 & 1985 & 0.164 \\
\hline Male (\%) & 90.98 & 92.25 & 89.84 & 0.171 \\
\hline White (\%) & 88.53 & 97.02 & 80.93 & $<0.001$ \\
\hline \multicolumn{5}{|l|}{ Pop genre (\%) } \\
\hline Rock & 89.76 & 94.83 & 85.2 & $<0.001$ \\
\hline$R \& B$ & 3.85 & 0.4 & 6.95 & $<0.001$ \\
\hline Electronica & 1.88 & 3.38 & 0.53 & $<0.001$ \\
\hline New age & 0.38 & 0.8 & 0 & 0.106 \\
\hline Punk & 0.28 & 0.6 & 0 & 0.21 \\
\hline Rap & 3.85 & 0 & 7.31 & $<0.001$ \\
\hline Dead 31/12/2005 (\%) & 9.4 & 5.57 & 12.83 & $<0.001$ \\
\hline \multicolumn{5}{|l|}{ Likely cause of death (\% of dead) } \\
\hline Chronic disorder (drug/alcohol)† & 8 & 3.57 & 9.72 & 0.544 \\
\hline Drug/alcohol overdose & 19 & 28.57 & 15.28 & 0.128 \\
\hline Accident (drug/alcohol related) & 4 & 7.14 & 2.78 & 0.665 \\
\hline Other accident & 16 & 21.43 & 13.89 & 0.535 \\
\hline Suicide & 3 & 3.57 & 2.78 & 0.657 \\
\hline Violence & 6 & 3.57 & 6.94 & 0.867 \\
\hline Cardiovascular disease & 14 & 3.57 & 18.06 & 0.12 \\
\hline Cancer & 20 & 21.43 & 19.44 & 0.823 \\
\hline Other & 10 & 7.14 & 11.11 & 0.823 \\
\hline
\end{tabular}

${ }^{*} p$ (probability) describes differences between North American and European pop stars. Medians are compared using Mann Whitney U tests, while percentages are compared using $\chi^{2}$.

†Chronic drug and alcohol disorders include liver, kidney and gastrointestinal diseases explicitly linked with substance use. Many of those deaths classed as suicides, violence related and other accidents, while likely to be linked with substance use, have only been categorised as alcohol- and drug-associated where references specifically detailed the link.

year eight when the upper 95\% CI for European pop star mortality exceeds expected mortality for the general population (fig 1), pop star mortality exceeds matched population mortality for all other years until after 25 years of fame. Further, European standardised pop star survival is consistently better than North American standardised survival (beyond the second year of fame) and, as length of fame increases, the gap between European and North American pop stars widens (fig 1). During this period, both North American and European artists experience mortality rates more than 1.7 times those for their counterpart general populations (table 3). However, after 25 years of fame the European and North American experiences differ sharply. For European artists, relative survival probability then increases until it is not significantly different from the population average (fig 1). By contrast, North American relative survival of pop stars demonstrates an increasing divergence from both their matched population survival and European pop star survival (fig l).

To illustrate how differences relate to contrasting general population mortality, we calculate pop star survival as estimated by Kaplan Meier survival curves plotted against corresponding matched general population curves. Figure 2 shows not only that survival for European artists is significantly higher than that for North American artists but also that there are substantial differences in survival between the two reference general populations (despite the two datasets not differing in age and sex). Thus, population survival at 35 years projected from cohort life tables for the North American reference population is $84 \%$ compared to $91 \%$ at 35 years for the corresponding European population projected from UK life tables. Consequently, the increasing gap in age standardised relative survival between North American and European pop stars occurs despite a greater fall in survival in the North American matched population than in Europe (fig 2).

\section{DISCUSSION}

In order to carry out a quantitative study of pop star mortality, we have had to make a number of assumptions. Firstly, our choice of sample utilised a specific international survey. ${ }^{18}$ However, its size, independence from this research and timing (recent but with enough time since polling for new artists to potentially experience some mortality) made it the most suitable choice. Our definition of date of fame was objective but had no established epidemiological criteria for fame on which to draw. However, as earliest date of chart success was used for most artists, this will tend to produce more conservative estimates of the effect of fame on mortality, with a choice of later dates of fame potentially exaggerating its immediate impact. Further, data were collected from a range of sources rather than official records of cause of death (table 1). Again, however, we cross-referenced over 430 websites, books and other sources, and although official data may have been beneficial, cause of death in such records may be contentious. Finally, we had to apply US and UK population mortality measures as proxies for North America and Europe. While differences may exist between countries, in each continent the vast majority of pop stars were from the UK or the USA (table 2). Consequently, although techniques have had to be creative, the results represent, at the least, a conservative estimate of additional mortality relating to musical fame and a substantial advance on descriptive assessments of individual pop star deaths.

Our results show that at between 2 and 25 years of fame, both North American and European pop stars tend to experience two to three times the risk of mortality expected in an average population matched by age, sex and, in North America, ethnicity (figs 1 and 2). Initially, pop stars experience similar relative mortality in both continents (table 3). However, results here contradict a common perception that pop and rock stars inhabit an environment independent of continent and wholly different from that of the general population in their countries of origin. Thus, although pop stars in both North America and Europe suffer similar relative increases in mortality (compared with local populations), differences in absolute levels of pop star mortality (North America vs Europe) are also consistent with geographical differences between 


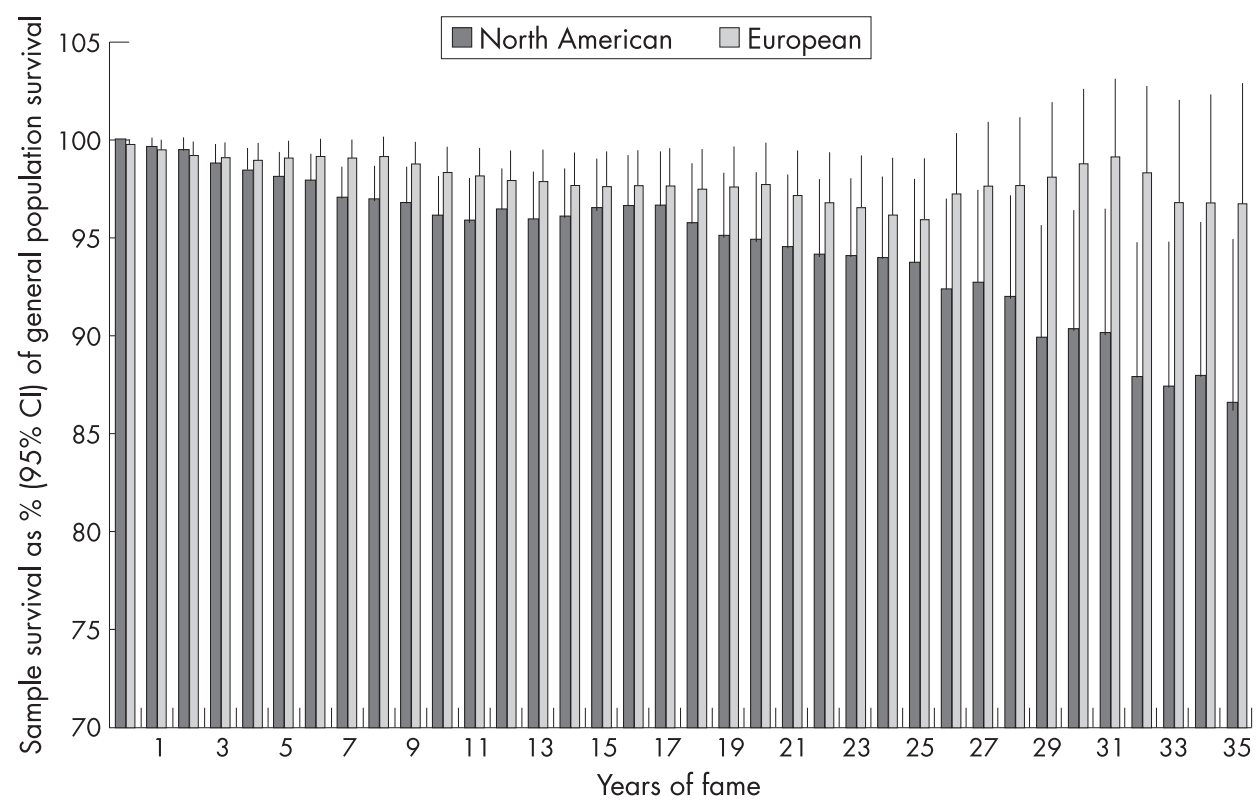

Figure 1 North American and European pop stars: age-standardised relative survival by years of fame. $\mathrm{Cl}$, confidence interval.

general populations (ie, North American pop stars and North American general populations die earlier; fig 2). Further, at 25 years post fame even the relative effects of stardom in each continent diverge. Here, European pop star mortality begins to return towards general population levels, while North American star mortality remains high (fig 2). This effect is not related to differences in ethnicity and, although not shown here, differences in relative survival between North American and European artists remain strong even when non-white American artists are excluded. In fact, as the general population survival for North American blacks is so much poorer than that for whites, exclusion of non-whites from both North American pop stars and matched populations increases differences between European and North American stars after 25 years of fame.

Divergence in mortality 25 years post fame might be explained by differences in longer-term experience of fame with more performing in later years (eg, nostalgic or reunion tours), continued media interest and associated stress and substance use in North American pop stars. ${ }^{26}$ However, this divergence may also reflect the pop star experience in North America being more likely to generate chronic ill health. In both continents, those reaching 25 years' fame also have a median age when chronic conditions and healthcare needs begin to escalate (around 50 years old; table 3). ${ }^{27}$ However, the North American pop stars appear more susceptible to chronic conditions (eg, cardiovascular disease; table 2) and consequently their associated excess mortality may continue later into life than the excess acute drug- and alcohol-related deaths more common in Europe (table 2). Moreover, the prognosis for pop stars who find themselves with poor health and impoverished in later life could also be substantially worse in North America should they have no health insurance. ${ }^{28}$

Consistent with other studies of pop stars, a disproportionate amount of their mortality appears to be related to alcohol and drug use (table 2). ${ }^{4}$ Pop stars' health and, in particular, substance use and other risk-taking tendencies should be addressed by the music industry not just in the short term but,

\begin{tabular}{|c|c|c|c|c|c|c|c|c|c|c|}
\hline & $\begin{array}{l}\text { Years } \\
\text { of fame }\end{array}$ & $\begin{array}{l}\text { Sample } \\
\text { size }\end{array}$ & $\begin{array}{l}\text { Average } \\
\text { age (years) }\end{array}$ & Survived & Died & $\begin{array}{l}\text { Sample } \\
\text { mortality }\end{array}$ & $\begin{array}{l}\text { Lower } \\
95 \% \mathrm{Cl}\end{array}$ & $\begin{array}{l}\text { Upper } \\
95 \% \mathrm{Cl}\end{array}$ & $\begin{array}{l}\text { Reference } \\
\text { mortality* }\end{array}$ & $\begin{array}{l}\text { Mortality } \\
\text { ratio }\end{array}$ \\
\hline \multirow{8}{*}{ European } & 0 & 503 & 24 & 502 & 1 & 0.20 & 0.01 & 1.10 & 0.00 & NA \\
\hline & 5 & 503 & 29 & 496 & 7 & 1.39 & 0.56 & 2.85 & 0.46 & 3.05 \\
\hline & 10 & 457 & 34 & 445 & 12 & 2.63 & 1.36 & 4.54 & 0.98 & 2.68 \\
\hline & 15 & 375 & 39 & 360 & 15 & 4.00 & 2.26 & 6.51 & 1.63 & 2.46 \\
\hline & 20 & 337 & 44 & 321 & 16 & 4.75 & 2.74 & 7.60 & 2.56 & 1.86 \\
\hline & 25 & 253 & 48 & 233 & 20 & 7.91 & 4.90 & 11.94 & 3.97 & 1.99 \\
\hline & 30 & 152 & 53 & 141 & 11 & 7.24 & 3.67 & 12.58 & 6.08 & 1.19 \\
\hline & 35 & 102 & 58 & 90 & 12 & 11.76 & 6.23 & 19.65 & 8.85 & 1.33 \\
\hline \multirow[t]{8}{*}{ North American } & 0 & 561 & 26 & 561 & 0 & 0.00 & 0.00 & 0.66 & 0.00 & NA \\
\hline & 5 & 561 & 31 & 544 & 17 & 3.03 & 1.77 & 4.81 & 0.98 & 3.10 \\
\hline & 10 & 495 & 36 & 466 & 29 & 5.86 & 3.94 & 8.32 & 2.08 & 2.82 \\
\hline & 15 & 362 & 40 & 337 & 25 & 6.91 & 4.52 & 10.03 & 3.57 & 1.93 \\
\hline & 20 & 291 & 46 & 261 & 30 & 10.31 & 7.06 & 14.39 & 5.49 & 1.88 \\
\hline & 25 & 262 & 50 & 226 & 36 & 13.74 & 9.81 & 18.51 & 7.96 & 1.73 \\
\hline & 30 & 196 & 55 & 157 & 39 & 19.90 & 14.55 & 26.18 & 11.30 & 1.76 \\
\hline & 35 & 144 & 59 & 105 & 39 & 27.08 & 20.02 & 35.11 & 15.77 & 1.72 \\
\hline
\end{tabular}

*Reference population mortality is calculated from published UK cohort life tables for European populations and from cohort life tables calculated from US decennial (period) life tables for North America (see Methods section for details). 


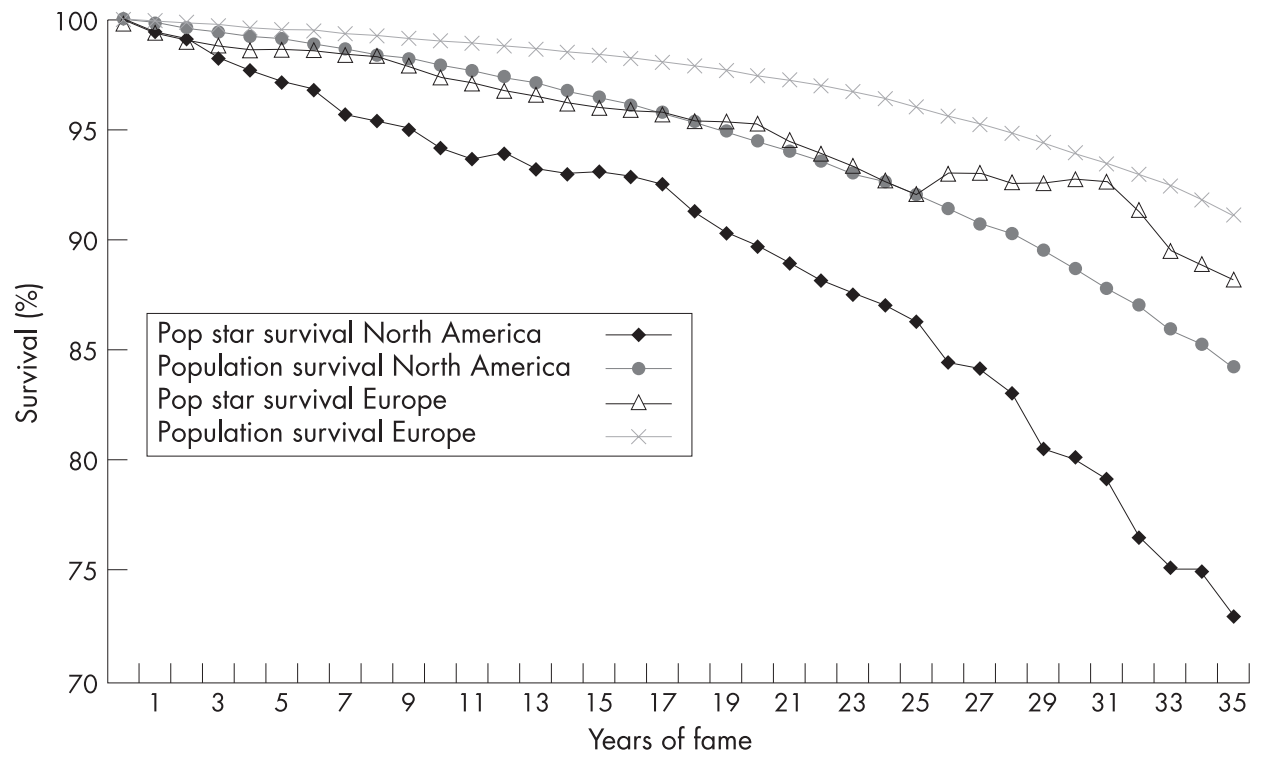

Figure 2 Comparative survival curves for North American and European pop stars and demographically matched general populations. with a prolonged period of increased mortality following fame, their long term health should also be examined. Encouragingly, comparisons of 5-year mortality in those reaching fame before and after 1980 suggest that immediate increases in mortality following fame have reduced. However, even in the 1980s and 1990s, 1.6\% of pop stars had died within 5 years of fame. Qualitative studies of those who reach professional or semiprofessional rock and pop musician status (but not stardom) suggest they also suffer elevated levels of stress, depression and substance use. ${ }^{3}{ }^{10}$ While links between pop stars and this group of other professional and semi-professional musicians are largely unstudied, the size of this group and the opportunity for genre leaders to influence their behaviour should not be underestimated. In the late 1970s, there were an estimated 5000 bands in the San Francisco Bay Area alone, ${ }^{30}$ while in the UK, one in ten children (age 7-16) aspire to be a pop star when they grow up. ${ }^{31}$ Television programmes such as The X Factor (UK) indicate how many more would follow this path given the chance (eg, over 100000 people applied for The X Factor 2006). ${ }^{32}$ More broadly, debate continues over whether individuals attracted even as fans to certain music genres (eg, rap music) associated with risk taking (eg, drug use) are already involved in risk taking when they start to follow this music or whether they

\section{What this paper adds}

- Using rock and pop stars we explore and describe a novel methodology for examining survival in specific populations where lack of population denominators precludes conventional techniques.

- Results indicate that rock and pop stars suffer nearly double the mortality of demographically matched general populations in North America and Europe.

- Internationally rock and pop stars, along with other media celebrities, are being utilised to promote positive health messages. However, results suggest caution should be exercised when utilising rock and pop stars until more is understood about how their personal profiles influence public behaviour. subsequently develop such behaviour. ${ }^{16}$ However, recent studies suggest that preference for certain genres actually precedes development of problem behaviours and consequently music associations (eg, being a rap fan) may contribute to anti-social behaviour. $^{33}$

The methodological approach developed here (although analogous to methods utilised for measuring mortality in soap opera characters $)^{34}$ provides a novel technique for assessing differential mortality and survival for populations observed over an extended time period. Importantly, it is applicable where conventional techniques to calculate population-standardised mortality ratios are precluded by an inability to estimate appropriate population denominators. Here, these methodologies have quantified significant additional mortality associated with rock and pop stardom. This study could not

\section{Policy implications}

- While policy has directed considerable attention to the health of the most deprived, relatively little work has addressed the health of the rich and famous. In particular, the behaviour of celebrity individuals may influence significant proportions of young people and should be better understood.

- Despite some indications that mortality relating to pop stardom has fallen in recent years, it remains substantially higher than in the general population. Such mortality is likely to be accompanied by more widespread morbidity among the most famous as well as lesser celebrities and would-be pop stars. Collaborative work between health and music industries should be undertaken to address this.

- Increasingly, communication of health-promoting messages to young people is being undertaken by pop stars and other celebrity figures. However, more needs to be learnt about how such interventions actually affect young people's behaviour and whether they work to promote positive health messages or, conversely, risk-taking lifestyles. 
distinguish whether pop fame contributed to reduced survival or whether those achieving fame were already predisposed to additional mortality. Consequently, despite some signs that mortality associated with pop star fame may have reduced in recent decades, the continued excess health risk experienced by such artists should be further examined. In particular, in the music industry, factors such as stress, changes from popularity to obscurity, and exposure to environments where alcohol and drugs are easily available, can all contribute to substance use as well as other self-destructive behaviours. ${ }^{29}$ Here, just as in the general population, levels of substance use, suicide, violence and other risk behaviours can be reduced not just on an individual basis but through altering the environment. ${ }^{35}$

More widely, public health consideration needs to be given to preventing music icons promoting health-damaging behaviours amongst their emulators and fans. Stars could play an important part in improving health behaviours and, across a variety of countries, major figures have been used to promote health messages. However, the success of such interventions largely depends on how much of pop stars' appeal to young people is as a result of their links with risk-taking behaviours. Although poorly understood, the strength of such links and ability to alter them determines, in part, pop stars' negative effects on public health and potential to act as positive health models. Where pop star behaviour remains typified by risk taking and substance use, it is unlikely that youths will see any positive health messages they champion as credible and potentially risky behaviours may actually be promoted. Consequently, collaborations between public health and music industries should not just focus on affecting the behaviour of fans but should also consider improving the health behaviour of artists to both protect them from ill-health and premature mortality and to ensure any status as positive health role models is sustainable and credible.

\section{ACKNOWLEDGEMENTS}

Our sincere thanks to Sara Edwards, Beccy Manning, Sara Hughes, Phil Wheater and Jeremy Hooper for the significant contributions they have made identifying and collating information utilised in this paper. Many other individuals have also provided texts, references and website addresses that helped us to develop this paper and we are grateful for their help.

\section{Authors' affiliations}

Mark A Bellis, Clare Lushey, Karen Hughes, Karen Tocque, John R Ashton, Centre for Public Health, Liverpool John Moores University, Liverpool, UK Tom Hennell, Public Health Group, Government Office for the North West of England, Manchester, UK

Competing interests: None declared.

\section{REFERENCES}

1 Thomson D. Better to burn out: the cult of death in Rock'n'Roll. New York: Thunder's Mouth Press, 1999.

2 Raeburn SD. Psychological issues and treatment strategies in popular musicians. A review, part 1. Med Probl Perform Art 1999;14:171-9.

3 Raeburn SD. Occupational stress and coping in a sample of professional rock musicians. Second of two parts. Med Probl Perform Art 1987;2:77-82.

4 Raeburn SD. Occupational stress and coping in a sample of professional rock musicians. First of two parts. Med Probl Perform Art 1987;2:41-8.
5 Herer B. The longevity and causes of death of jazz musicians, 1990-1999. Med Probl Perform Art 2000;15:119-22.

6 Patalano F. Psychosocial stressors and the short life spans of legendary jazz musicians. Percept Mot Skills 2000;90:435-6.

7 National Statistics. Death registrations in England and Wales, 2004: causes. Health Stat Q 2005;26: 62-9, www.statistics.gov.uk/downloads/theme_health/ HSQ26.pdf (accessed 10 June 2007).

8 Miniño AM, Heron MP, Smith BL, eds. Deaths: preliminary data for 2004 National Vital Statistics Reports 2006;54(19)

9 Wood J, Hennell T, Jones A, et al. Where wealth means health: illustrating inequality in the North West. Liverpool: North West Public Health Observatory, Centre for Public Health, Liverpool John Moores University, 2006.

10 Raeburn SD. Psychological issues and treatment strategies in popular musicians. A review, part 2. Med Probl Perform Art 2000;15:6-16.

11 Bromnick RD, Swallow BL. I like being who I am: a study of young people's ideals. Educ Stud 1999;25:117-28.

12 Boon SD, Lomore CD. Admirer-celebrity relationships among young adults: explaining perceptions of celebrity influence on identity. Human Commun Res 2001;27:432-65.

13 Newcomb MD, Mercurio CS, Wollard CA. Rock stars in anti-drug abuse commercials: an experimental study of adolescents' reactions. J Appl Soc Psychol 2000;30:1160-85.

14 Ter Bogt TFM. "Partying" hard: party style, motives for effects of MDMA use at rave parties. Subst Use Misuse 2005;40:1479-1502.

15 Arnett J. The soundtrack of recklessness: musical preferences and reckless behavior among adolescents. J Adolesc Res 1992;7:313-31.

16 Miranda D. Claes M. Rap music genres and deviant behaviors in FrenchCanadian adolescents. J Youth Adolesc 2004;33:113-22.

17 Arnett J. Heavy metal music and reckless behavior among adolescents. J Youth Adolesc 1991;20:573-92

18 Larkin C. All-time top 1000 albums, 3rd edn. London: Virgin Publishing, 2000.

19 Katz GJ. Death by rock \& roll: the untimely deaths of the legends of rock. New York: Carol Publishing Group, 1995.

20 York W. Who's who in rock music. New York: Charles Scriber's Sons, 1982.

21 Allmusic. Website, 2006. www.allmusic.com.

22 Coleman MP, Babb P, Damiecki P, et al. Cancer survival trends in England and Wales, 1971-1995: deprivation and NHS region, Studies in Medical and Population Subjects No 61. London, UK: Stationery Office, 1999.

23 Government Actuary's Department. Period and cohort expectations of life. http://www.gad.gov.uk/Life_Tables/Period_and_cohort_eol.htm (accessed 10 June 2007).

24 US Bureau of the Census. U.S. population estimates, by age, sex, race, and Hispanic origin: 1980 to 1991, Current population reports, series P-25-1095. Washington: Government Printing Office, 1993.

25 National Center for Health Statistics. U.S. decennial life tables for 1989-91, Vol 1, no 1. Hyattsville, Maryland: US Department of Health and Human Services, 1997

26 Strausbaugh J. Rock til you drop: the decline from rebellion to nostalgia. New York: Verso, 2003.

27 Meerding WJ, Bonneux L, Polder JJ, et al. Demographic and epidemiological determinants of healthcare costs in Netherlands: cost of illness study. BMJ 1998:317:111-15.

28 State Health Access Data Assistance Center (SHADAC). The coverage gap: a state-by-state report on access to care. Minneapolis: University of Minnesota, 2006.

29 Raeburn SD, Hipple J, Delaney W, et al. Surveying popular musicians' health status using convenience samples. Med Probl Perform Art 2003;18:113-19.

30 Hirschberg L. How to be a rock ' $n$ ' roll star. Boulevards, 1981. Cited by Raeburn SD. Occupational stress and coping in a sample of professional rock musicians. First of two parts. Med Probl Perform Art 1987;2:41-8.

31 Co-operative Insurance Society. "Mummy, mummy, I want to be a doctor" - a child trust fund can help finance their dream. News release, 14 March 2005. http://www.prnewswire.co.uk/cgi/news/release?id = 141920 (accessed 10 June 2007).

32 ITV. The X Factor: show recap. www.xfactor.tv/page.asp?partid = 273 (accessed 10 June 2007).

33 Ter Bogt TFM. Pills, thrills \& problems: music and substance use. Proceedings of Club Health 2006, Piran, Slovenia.

34 Crayford T, Hooper R, Evans S. Death rates of characters in soap operas on British television: is a government health warning required? BMJ 1997;315:1649-52.

35 Bellis MA, Hughes $\mathrm{K}$, Lowey $\mathrm{H}$. Healthy nightclubs and recreational substance use: from a harm minimisation to a healthy settings approach. Addict Behav 2002;27:1025-35. 